\title{
ACCUMULATION OF p53 PROTEIN IN NORMAL, DYSPLASTIC, AND NEOPLASTIC BARRETT'S OESOPHAGUS
}

\author{
KAUSILIA K. KRISHNADATH, HUGO W. TILANUS, MARK VAN BLANKENSTEIN, FRE T. BOSMAN AND \\ ANDRIES H. MULDER \\ Departments of Surgery, Gastroenterology, and Pathology, Erasmus University, Rotterdam, \\ The Netherlands
}

Received 16 May 1994

Accepted 20 September 1994

\begin{abstract}
SUMMARY
Accumulation of $\mathrm{p} 53$ protein was determined by immunohistochemistry in archival material of biopsy specimens from 102 patients with Barrett's oesophagus with different grades of dysplasia, in 24 oesophageal adenocarcinomas associated with Barrett's oesophagus, and in 23 cases of metaplastic epithelium adjacent to these carcinomas. Immunostaining for the $\mathrm{p} 53$ protein was found in 23/102 (23 per cent) cases of the Barrett's oesophagus biopsies and in 12/23 ( 52 per cent) cases of Barrett's oesophagus adjacent to adenocarcinoma. Significant correlations were found between the grade of dysplasia and p53 immunoreactivity in both Barrett's biopsies without adenocarcinoma $(P<0.001)$ and Barrett's oesophagus adjacent to adenocarcinoma $(P<0.05)$. In the adenocarcinomas, intense nuclear immunohistochemical staining for p53 was diffusely or focally present in 20/24 (83 per cent) of the specimens. In Barrett's oesophagus, p53 is a progression marker with high expression in high-grade dysplasia ( 89 per cent) and adenocarcinoma ( 83 per cent).
\end{abstract}

KEY WORDS-Barrett's oesophagus, dysplasia, oesophageal adenocarcinoma, p53, immunohistochemistry.

\section{INTRODUCTION}

In Barrett's oesophagus, the stratified squamous epithelium of the distal oesophagus is replaced by metaplastic columnar epithelium. ${ }^{1,2}$ Patients with Barrett's oesophagus have a 30 to 40 -fold increased risk of developing oesophageal adenocarcinoma. ${ }^{3,4}$ Although adenocarcinoma in Barrett's oesophagus is preceded by epithelial dysplasia, the time course of progression of simple metaplasia into dysplastic Barrett's epithelium and ultimately into infiltrating adenocarcinoma is unknown. Furthermore, grading of dysplasia is to a certain extent subjective, leading to significant inter-observer variation. Consequently, there is insufficient consensus as to the optimal treatment of these patients. Objective prognostic criteria

Addressee for correspondence: K. K. Krishnadath, Department of Pathology, Erasmus University, P.O. Box 1738, 3000 DR Rotterdam, The Netherlands. predicting which cases of Barrett's epithelium will progress towards malignancy are therefore of major importance. Previous immunohistochemical studies with proliferation markers have already shown higher proliferation rates in dysplastic Barrett's epithelium ${ }^{5}$ and abnormalities measured by DNA flow cytometry may precede malignancy. ${ }^{6}$

During the past few years, interest in tumour suppressor genes and proteins in (pre)malignant lesions has intensified. The appearance of the p53 tumour suppressor protein has been reported in a wide variety of malignant and premalignant conditions. $^{7-14}$ p53 immunoreactivity has been reported in $62-87$ per cent of oesophageal adenocarcinomas, and in non-dysplastic and dysplastic Barrett's oesophagus. ${ }^{15-18}$

The aim of the present study was to determine whether immunohistochemically-detectable p53 protein accumulation occurs along with the development of dysplasia in Barrett's oesophagus. 


\section{MATERIALS AND METHODS}

\section{Tissues}

p53 immunoreactivity was studied in archival biopsies taken between 1980 and 1992 from 102 patients with Barrett's oesophagus with various degrees of dysplasia but without adenocarcinoma. The number of biopsies per patient varied from one to 12. Furthermore, paraffin-embedded tissue blocks from 24 oesophagus-cardia resection specimens with adenocarcinoma in Barrett's oesophagus encountered between 1990 and 1992 were investigated. All patients had undergone cardiacoesophageal resection with gastric tube interposition. Surgery was performed at a mean age of 62 years (range $45-80$ years). None of the patients with adenocarcinoma had received chemo- or radiotherapy prior to surgery. One paraffin block containing adenocarcinoma was selected in each case. To determine the efficacy of p53 immunostaining in paraffin-embedded tissues, immunohistochemistry for the detection of $\mathrm{p} 53$ protein was performed on corresponding fresh frozen samples of 20 of the adenocarcinomas. Barrett's epithelium adjacent to the tumour was found in 23 cases. In one case, Barrett's oesophagus was diagnosed in biopsy specimens prior to oesophageal resection. Normal gastric-cardiac mucosa was used for control purposes.

\section{Histopathological criteria}

The histological sections were reviewed by two pathologists (AHM and FTB). Tumour staging was performed according to pTNM criteria. Barrett's oesophagus was defined as columnar epithelial lining of the oesophagus for at least $3 \mathrm{~cm}$ proximal to the gastro-oesophageal junction. All cases had specialized columnar-type metaplasia characterized by the presence of intestinal goblet cells. Dysplasia was graded into three categories following criteria revised by Reid et al.: ${ }^{19}$ negative; indefinite or low-grade dysplasia; and high-grade dysplasia. Slides were coded and scoring of p53 immunoreactivity was performed independently of the grading of the sections.

\section{Immunohistochemistry}

Cryostat sections $(5 \mu \mathrm{m})$ of fresh tissues were air-dried and fixed in acetone $\left(-20^{\circ} \mathrm{C}\right)$. After blocking of endogenous peroxidase activity and rinsing in phosphate-buffered saline (PBS, $\mathrm{pH}$ 7-4), p53 protein labelling was performed by the standard peroxidase/anti-peroxidase method (Dakopatts Z 259; Sigma P 2416, St Louis, MO, U.S.A.).

DO-7 (Dakopatts, Glostrup, Denmark), an Ig2b kappa monoclonal antibody recognizing an epitope in the $\mathrm{N}$-terminus between amino acids 35 and 45 of human p53 protein, was used on formalin-fixed, paraffin-embedded tissues.

For paraffin sections, an antigen retrieval method was applied. ${ }^{20}$ After blocking of endogenous peroxidase, p53 labelling with DO-7 was performed by the streptavidin-biotin complex procedure. The sections were preincubated for $15 \mathrm{~min}$ at $37^{\circ} \mathrm{C}$ with 10 per cent normal goat serum, diluted in PBS. DO-7, diluted $1 / 25$ in PBS, was added for overnight incubation at $4^{\circ} \mathrm{C}$. The negative controls were incubated with PBS only. The sections were subsequently incubated with biotinylated goat-anti-mouse $\operatorname{IgG}(1 / 400$ in PBS, Dakopatts), rinsed, and finally incubated with a streptavidin-biotinylated horseradish peroxidase complex (Dakopatts). Sections were developed for $7 \mathrm{~min}$ in 3,3'-diaminobenzidine tetrachloride.

\section{Microscopical evaluation}

Positive immunohistochemistry with the DO-7 p53 antibody was defined as moderate or intense brown nuclear staining. Cytoplasmic staining was not found. In a semi-quantitative scoring approach, two staining patterns were distinguished: a focal pattern, with $>10$ per cent of nuclei positive in clusters, was mostly found in non-dysplastic and low-grade dysplastic Barrett's oesophagus. The focal staining was mostly confined to glandular epithelium (Fig. 1a). A diffuse staining pattern with $>10$ per cent of positive nuclei scattered through the tissue was seen in most adenocarcinomas and high-grade dysplasia (Fig. 1b).

\section{RESULTS}

p53 labelling by standard immunohistochemistry from unfixed frozen sections of 20 Barrett's adenocarcinomas gave results similar to those obtained after the use of the antigen retrieval method on corresponding paraffinembedded, formalin-fixed sections of these tumours. 

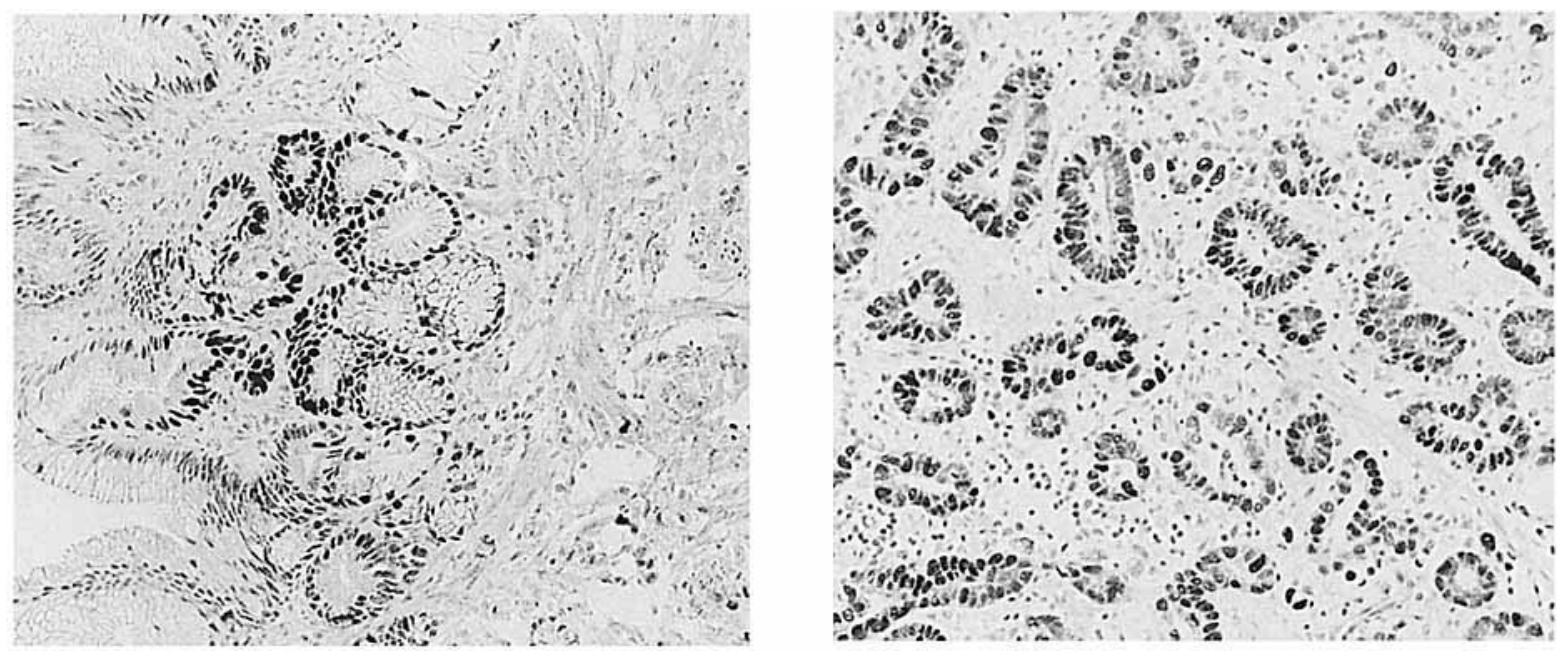

Fig. 1-(a) Focal immunohistochemical staining of the p53 protein with the monoclonal antibody DO-7 in a paraffin-embedded section of a Barrett's oesophagus biopsy with low-grade dysplasia. (b) Moderately differentiated oesophageal adenocarcinoma showing a diffuse immunostaining pattern of tumour cells. Both sections were counterstained by haematoxylin. A $\times 10$ objective was used

Table I-p53 immunostaining in biopsies from Barrett's oesophagus

\begin{tabular}{lrcc}
\hline $\begin{array}{l}\text { Degree of } \\
\text { dysplasia }\end{array}$ & $n$ & \multicolumn{1}{c}{$\begin{array}{c}\text { Positive p53 } \\
\text { immunostaining }\end{array}$} \\
\hline No & 50 & $3(6 \%)$ & \\
Indefinite/low & 43 & $12(28 \%)$ & $8<0 \cdot 001^{*}$ \\
High & 9 & $8(89 \%)$ & \\
Total & 102 & $23(23 \%)$ & \\
\hline
\end{tabular}

*P value as calculated by the Trend test. ${ }^{21}$

\section{Normal cardia and oesophageal mucosa}

Normal cardia tissue taken from the resection material was used for control purposes. All 24 cases were negative for $\mathrm{p} 53$. Weak nuclear staining with DO-7 was sporadically seen in the basal layer of normal squamous epithelium.

\section{Barrett's epithelium}

Immunohistochemical assessment of biopsy material from 102 patients with Barrett's epithelium without carcinoma revealed intense nuclear p53 staining in 23 of 102 ( 23 per cent) biopsies. A significant correlation was found between the grade of dysplasia and p53 staining (Trend test: $P<0.001$, Table I). Staining for p53 was found in 8 of 9 ( 89 per cent) cases with high-grade dysplasia, 12 of 43 ( 28 per cent) cases with indefinite or low-grade dysplasia, and 3 of 50 (6 per cent) cases of simple metaplasia (Table I). Staining was focal in all non-dysplastic, in eight indefinite/low-grade dysplastic, and in two high-grade dysplastic cases (Fig. 1a). In ten cases, four indefinite/low-grade and six high-grade, staining was diffuse.

\section{Barrett's epithelium adjacent to adenocarcinoma}

Staining for p53 in Barrett's epithelium adjacent to the infiltrating tumour was performed in 23 cases. p53 staining correlated significantly with the grade of dysplasia (Trend test $P<0.05$, Table II). Eight of nine ( 89 per cent) of the severely dysplastic cases showed diffuse staining. In 4 of 11 (36 per 
Table II-p53 immunostaining in Barrett's oesophagus adjacent to adenocarcinoma

\begin{tabular}{lrll}
\hline Degree of dysplasia & $n$ & \multicolumn{1}{c}{$\begin{array}{c}\text { Positive p53 } \\
\text { immunostaining }\end{array}$} \\
\hline No & 3 & $0(0 \%)$ & \\
Indefinite/low & 11 & $4(36 \%)$ & $P<0.05^{*}$ \\
High & 9 & $8(89 \%)$ & \\
Total & 23 & $12(52 \%)$ & \\
\hline
\end{tabular}

*P value as calculated by the Trend test. ${ }^{21}$

Table III $-\mathrm{p} 53$ immunostaining in adenocarcinomas in Barrett's oesophagus

\begin{tabular}{lcc}
\hline Tumour stage* $^{*}$ & $n$ & $\begin{array}{c}\text { Positive p53 } \\
\text { immunostaining } \dagger\end{array}$ \\
\hline T1 & 6 & $6(100 \%)$ \\
T2 & 6 & $5(83 \%)$ \\
T3/4 & 12 & $9(75 \%)$ \\
Total & 24 & $20 \quad(83 \%)$ \\
\hline
\end{tabular}

*Tumour stage according to TNM classification; T1: tumour infiltration in submucosa; T2: tumour infiltration in muscularis propria; T3/T4: tumour infiltration in adventitia and beyond.

$\dagger$ Focal or diffuse nuclear immunostaining.

cent) cases with indefinite or low-grade dysplasia, focal p53 staining was observed. p53 immunostaining was not observed in the three nondysplastic epithelia adjacent to tumour. In a total of 11 cases of adjacent Barrett's epithelium, p53 immunoreactivity was not seen; four of these were adjacent to adenocarcinomas lacking p53 staining as well.

\section{Adenocarcinoma in Barrett's oesophagus}

The 24 cases of adenocarcinoma in Barrett's oesophagus were distributed according to tumour stage as shown in Table III. In 20 of 24 cases ( 83 per cent), diffuse (19 cases) or focal ( 1 case) nuclear immunohistochemical staining for p53 was found (Fig. 1b). Staining was similar in the three stage groups, with a slight preponderance of negative cases in the advanced tumours. No significant correlation was found between p53 staining and the grade of differentiation.

\section{DISCUSSION}

The study of different stages in carcinogenesis in a model which includes early stages of cancer development has important clinical implications. Barrett's oesophagus might serve as a unique model in which early changes preceding full blown malignancies are encountered. Patients suffering from Barrett's changes are monitored by periodic endoscopies and biopsies, allowing longitudinal follow-up studies. Although Barrett's oesophagus may lead to malignancy, the course of development of carcinoma in the individual can hardly be predicted by histopathology. It is therefore of paramount importance to trace more objective parameters which are associated with dysplasia and which reflect the progression of malignancy. p53 mutation, a common genetic event in many human malignancies, ${ }^{7-14}$ might be such a parameter. Positive p53 protein immunostaining is generally assumed to accompany gene mutations, 
which result in increased stability and consequent accumulation of mutated 553 protein. ${ }^{22}$ Intense immunostaining with the DO-7 anti-p53 antibody has proved to be highly specific for mutated $\mathrm{p} 53$. $^{23}$

In the present study nuclear $\mathrm{p} 53$ protein staining was shown in 23 of 102 ( 23 per cent) biopsies from Barrett's oesophagus with different grades of dysplasia and in 12 of 23 (52 per cent) Barrett's epithelia adjacent to tumour. In these specimens p53 staining correlated significantly with the grade of dysplasia $(P<0.001$ and $P<0.05$, respectively), with a high prevalence ( 89 per cent) in high-grade dysplasia. The number of cases with nuclear p53 immunostaining in Barrett's oesophagus in our study is somewhat higher than previously reported. ${ }^{16-18}$ Differences in the applied monoclonal antibodies and/or in the histochemical techniques used may account for the discrepancies.

Positive p53 immunostaining in Barrett's oesophagus with absent or low-grade dysplasia $^{16-18}$ may indicate that $\mathrm{p} 53$ protein accumulation is an early event during carcinogenesis in Barrett's oesophagus. Focally staining areas in these lesions may be associated with p53 gene mutations; moreover, these clones may be precursors of progressive lesions with ultimately diffuse p53 staining. p53 gene mutations in non-dysplastic and minimally dysplastic Barrett's oesophagus were demonstrated by the polymerase chain reaction and sequence analysis by Casson et al. ${ }^{24}$ Alternatively, increased amounts of wild-type p53 protein, resulting in positive immunostaining, were noticed in irradiated and highly proliferative tissues. $^{25,26}$ Since the DO-7 monoclonal antibody also reacts with wild-type p53 protein and since proliferation rates are high in Barrett's oesophagus, ${ }^{5}$ we cannot rule out that in a subset of cases immunostaining was a result of immunoreaction of DO-7 with wild-type p53. Furthermore, using monoclonal antibodies, certain conditions may give false-negative results, such as when the epitope which is recognized by the DO-7 monoclonal antibody is mutated or inaccessible as a consequence of complex formation of p53 with other proteins. ${ }^{27}$ On the other hand, complete absence of p53 protein due to loss of both p53 alleles, non-sense mutations, or stop codons in the gene would not be distinguishable from normal levels of wild-type p53 by immunohistochemical techniques; in both conditions, staining would be negative.
In the present study, p53 immunostaining was observed in 20 of 24 ( 83 per cent) adenocarcinomas in Barrett's oesophagus. In oesophageal adenocarcinomas associated with Barrett's oesophagus, Younes et al. ${ }^{16}$ reported p53 immunostaining in 7 of 8 ( 87 per cent) cases. In addition, in a follow-up series of 24 Barrett's oesophagus patients, three cases progressed to high-grade dysplasia, two of which had p53 immunostaining and low-grade dysplasia in initial biopsy specimens. ${ }^{16}$ In the study of Blount et al. ${ }^{15}$ p53 immunostaining was found in 8 of 13 (62 per cent) oesophageal adenocarcinomas, whereas allelic loss of the p53 gene (17p) was detected in 92 per cent of cases. Although we did not find a correlation between the tumour grade and p53 protein accumulation, a trend between increasing p53 expression with reduced tumour differentiation was recently seen in a larger series. ${ }^{18}$ The absence of p53 staining in four tumours and in two cases of highly dysplastic Barrett's oesophagus may indicate that malignant progression is possible without involvement of the p53 gene. ${ }^{28}$

p53 staining in tumour and in adjacent Barrett's epithelium does not necessarily correspond. In 7 of 19 patients, Barrett's epithelium adjacent to p53positive tumour tissue showed no p53 immunostaining. None of these cases showed severe dysplasia. A similar observation has been reported by Flejou et al., ${ }^{29}$ who found that p53 immunostaining in Barrett's oesophagus adjacent to p53positive adenocarcinomas was only present in cases where the epithelium was severely dysplastic. Recently Hardwick et al. ${ }^{30}$ found positive p53 immunostaining in ten cases of dysplastic Barrett's epithelium, all adjoining p53-positive oesophageal adenocarcinomas. In the present study, four carcinomas did not show p53 immunostaining. In all these cases adjacent Barrett's epithelia, regardless of the degree of dysplasia, were negative as well.

In conclusion, p53 protein accumulates in Barrett's adenocarcinoma and in premalignant lesions, correlating with the degree of dysplasia. p53 immunostaining might therefore constitute a useful diagnostic tool. However, the predictive value of p53 immunostaining in biopsies without high-grade dysplasia should be determined in prospective follow-up studies.

\section{REFERENCES}

1. Barrett NR. Chronic peptic ulcer of the oesophagus and oesophagitis. Br J Surg 1950; 38: 175-182.

2. Spechler SJ. Barrett's oesophagus. Gastroenterology 1992; 8: 573 578. 
3. Spechler SJ, Robbins AH, Rubins HB, et al. Adenocarcinoma and Barrett's oesophagus. An overrated risk? Gastroenterology 1984; 87: 927-933.

4. Van der Veen AH, Dees J, Blankensteijn JD, et al. Adenocarcinoma in Barrett's oesophagus: an overrated risk. Gut 1989; 30: 14-18

5. Reid BJ, Sanchez CVA, Blount PL, Levine DS. Barrett's oesophagus: cell cycle abnormalities in advancing stages of neoplastic progression. Gastroenterology 1993; 105: 119-129.

6. Fennerty MB, Sampliner RE, Garewal HS. Review article: Barrett's oesophagus - cancer risk, biology and therapeutic management. Aliment Pharmacol Ther 1993; 7: 339-345.

7. Porter PL, Gown AM, Kramp SG, et al. Widespread p53 overexpression in human malignant tumors. An immunohistochemical study using methacarn-fixed, embedded tissue. Am J Pathol 1992; 140: $145-153$.

8. Nigro JM, Baker SJ, Preisinger AC, et al, Mutations in the p53 gene occur in diverse human tumor types. Nature 1989; 342: 705-708.

9. Hollstein M, Sidransky D, Vogelstcin B, et al. p53 mutations in human cancers. Science 1991; 253: 49-53.

10. Campo E, de la Callẽ Martin O, Miquel $\mathrm{R}$, et al. Loss of heterozygosity of $\mathrm{p} 53$ gene and $\mathrm{p} 53$ protein expression in human colorectal carcinomas. Cancer Res 1991; 51: 4436-4442.

11. Caamano J, Ruggeri B, Momiki S, et al. Detection of p53 in primary lung tumors and nonsmall cell lung carcinoma cell lines. Am J Pathol 1991; 139: 839-845.

12. Van den Berg FM, Tigges AJ, Schipper ME, et al. Expression of the nuclear oncogene $\mathrm{p} 53$ in colon tumours. $J$ Pathol 1989; 157: $193-199$.

13. Kaklamanis L, Gatter KC, Mortensen $\mathrm{N}$, et al. p53 expression in colorectal adenomas. Am J Pathol 1993; 1: 87-93.

14. Kros JM, Krishnadath KK, Godschalk JCJ, et al. Expression of p53 in oligodendrogliomas. J Pathol 1993; 171: 285-290.

15. Blount PL, Ramel S, Raskind $\mathrm{WH}$, et al. $17 \mathrm{p}$ allelic deletions and p53 protein overexpression in Barrett's adenocarcinoma. Cancer Res 1991; 51: 5482 5486.

16. Younes M, Lebovitz RLM, Lechago LV, Lechago J. p53 protein accumulation in Barrett's metaplasia, dysplasia and carcinoma: a follow-up study. Gastroeneterology 1993; 105: 1637-1642.

17. Ramel S, Reid BJ, Sanchez CA, et al. Evaluation of p53 in Barrett's oesophagus by two-parameter flow cytometry. Gastroenterology 1992; 102: 1220-1228.
18. Symmans PJ, Linehan JM, Brito MJ, Filipe MI. p53 expression in Barrett's oesophagus, dysplasia, and adenocarcinoma using antibody DO-7. I Pathol 1994; 173; 221-226.

19. Reid BJ, Weinstein WM, Lewin KJ, el al. Endoscopic biopsy can detect high-grade dysplasia or early adenocarcinoma in Barrett's oesophagus without grossly recognizable neoplastic lesions. Gastroenterology 1988; 94: 81-90.

20. Shi SR, Key ME, Kalra KL. Antigen retrieval in formalin-fixed, paraffin-embedded tissues: an enhancement method for immunohistochemical staining based on microwave oven heating of tissue sections. I Histochem Cytochem 1991; 39: 741-748.

21. Mantel N. Chi square tests with one degree of freedom. I Am Stat Assoc 1963; 58: 690-700.

22. Finlay CA, Hinds $\mathrm{PW}$, Tan $\mathrm{TH}$, et al. Activating mutations for transformation by $\mathrm{p} 53$ produce a gene product that forms an hsc 700-p53 complex with an altered half-life. Mol Cell Biol 1988; 8: 531-539.

23. Baas IO, Mulder JWR, Offerhaus GJA, Vogelstein B, Hamilton SR. An evaluation of six antibodies for immunohistochemistry of mutant p53 gene product in archival colorectal neoplasms. $J$ Pathol 1994; 172: $5-12$.

24. Casson AG, Mukhopadyay T, Cleary KR, Ro JY, Levin B, Roth JA. p53 gene mutations in Barrett's epithelium and oesophageal cancer. Cancer Res 1991; 51: 4495-4499.

25. Lane DP. p53 guardian of the genome. Nature $1992 ; 358: 15-16$.

26. Kuerbitz SJ, Plunkett BS, Walsh WV, Kastan MB. Wild-type p53 is a cell cycle checkpoint determinant following irradiation. Proc Natl Acad Sci USA 1992; 89: 7491-7495.

27. Vogelstein B, Kinzler KW. p53 function and dysfunction. Cell 1992; 70: $523-526$.

28. Levine AJ, Momand J, Finlay CA. The p53 tumour suppressor gene. Nature 1991; 351: 453-456.

29. Flejou JF, Potet F, Mureau F, et al. Overexpression of p53 protein in Barrett's syndrome with malignant transformation. J Clin Pathol 1993; 46: 330-334.

30. Hardwick RH, Shepherd NA, Moorghen M, Newcomb PV, Alderson D. Adenocarcinoma arising in Barrett's oesophagus. Evidence for the participation of p53 dysfunction in the dysplasia/ carcinoma sequence. Gut 1994; 35: 764-768. 